\title{
Biomassa e atividade microbianas do solo sob influência de chumbo e da rizosfera da soja micorrizada
}

\author{
Sara Adrián López de Andrade ${ }^{(1)}$ e Adriana Parada Dias da Silveira(1)
}

(1)Instituto Agronômico, Centro de Pesquisa e Desenvolvimento em Solos e Recursos Ambientais, Caixa Postal 28, CEP 13001-970 Campinas, SP. E-mail: apdsil@iac.sp.gov.br, saradrian@iespana.es

\begin{abstract}
Resumo - O objetivo deste trabalho foi avaliar o efeito da adição de chumbo $(\mathrm{Pb})$ ao solo na biomassa e atividade microbianas do solo sob influência da rizosfera de soja micorrizada. $\mathrm{O}$ trabalho foi realizado em casa de vegetação,

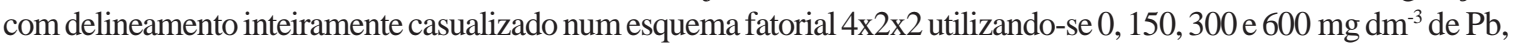
inoculação ou não do fungo micorrízico arbuscular (FMA), Glomus macrocarpum, e duas épocas de amostragem florescimento e maturação da soja. Avaliaram-se o $\mathrm{C}$ da biomassa microbiana, a liberação de $\mathrm{CO}_{2}$ do solo e a atividade de três enzimas, desidrogenase, fosfatase alcalina e arilssulfatase. $\mathrm{O} \mathrm{Pb}$ afetou negativamente $\mathrm{o}$ C da biomassa e a atividade da microbiota rizosférica, ocorrendo interação entre a presença de propágulos de FMA e o estádio de desenvolvimento da planta. A atividade da fosfatase alcalina foi a mais afetada pelas altas concentrações de $\mathrm{Pb}$ adicionadas ao solo, com redução de $60 \%$ na sua atividade, mostrando-se um indicador sensível do estresse metabólico da comunidade microbiana do solo causado pelo excesso de chumbo. A micorrização da soja influenciou de forma direta a microbiota rizosférica, resultando em maior atividade e biomassa, principalmente no estádio de maturação da soja. A microbiota do solo apresentou sintomas de estresse decorrentes da adição de chumbo.
\end{abstract}

Termos para indexação: respiração basal do solo, atividade enzimática, fungo micorrízico arbuscular, metal pesado, qualidade do solo.

\section{Soil microbial biomass and activity under the influence of lead addition and mycorrhizal soybean rhizosphere}

\begin{abstract}
The objective of this work was to evaluate the effects of lead addition on soil microbial biomass and activity under the influence of the rhizosphere of mycorrhizal soybean. The experimental design was completely

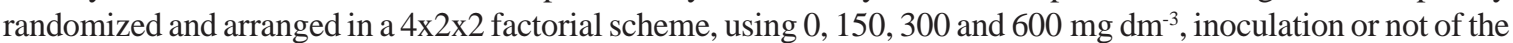
arbuscular mycorrhizal fungus (AMF) Glomus macrocarpum and two sampling periods: soybean flowering and maturity. Microbial biomass $\mathrm{C}$, soil respiration and the activity of three soil enzymes (deshydrogenase, alkaline phosphatase and arilsulphatase) were determined. The most affected enzyme was alkaline phophatase, whose activity was reduced in 60\%, and which was a sensible indicator of the microbial metabolic stress caused by high $\mathrm{Pb}$ concentrations. Soybean mycorrhization directly influenced the rhizospheric microbiota leading to higher activity and biomass, mainly at soybean maturity stage. Soil microbiota showed stress symptoms due to $\mathrm{Pb}$ addition to soil.
\end{abstract}

Index terms: soil basal respiration, enzimatic activity, arbuscular mycorrhizal fungus, heavy metal, soil quality.

\section{Introdução}

Os microrganismos do solo estão presentes tanto no solo como na rizosfera, onde realizam atividades metabólicas relevantes para o crescimento das plantas. A biota do solo desempenha funções no ecossistema, tais como armazenamento de água, decomposição de resíduos orgânicos, reciclagem de nutrientes, seqüestro e desintoxicação de substâncias tóxicas entre outras (Costanza et al., 1997).
Atualmente, a contaminação dos solos por metais pesados (MP) é um grave problema ambiental, por causa da sua persistência e alto poder de toxicidade (Reddy \& Prasad, 1990). Assim, há interesse em se utilizar características microbiológicas como indicadores da qualidade do solo (Doran \& Zeiss, 2000). Entre os MP, o $\mathrm{Pb}$, além de ser potencialmente tóxico, é pouco estudado em relação ao seu efeito na microbiota do solo, especialmente em solos tropicais. Esse metal, não essencial para os seres vivos, pode ser acumulado no solo e influ- 
enciar os microrganismos, e, conseqüentemente, afetar o funcionamento normal do ecossistema (Reddy \& Prasad, 1990).

Os efeitos prejudiciais dos MP no solo podem ser medidos pela biomassa microbiana (Brookes \& MacGrath, 1984), a composição de fosfolipídeos dos ácidos graxos (Bääth et al., 1998), a estrutura da comunidade (Reber, 1992) e a respiração e atividades enzimáticas (Valsecchi et al., 1995; Dias-Júnior et al., 1998; Chew et al., 2001).

Altas concentrações de MP diminuem a biomassa microbiana do solo (Fliebbach et al., 1994; Barajas Aceves et al., 1999). Valsecchi et al. (1995) observaram correlações negativas entre concentração de MP ( $\mathrm{Zn}, \mathrm{Pb}, \mathrm{Cu}, \mathrm{Cd}$, Ni e $\mathrm{Cr}$ ) e respiração do solo. Constataram também aumento no teor de matéria orgânica com o incremento da concentração de metais no solo, possivelmente em decorrência da menor eficiência na mineralização da matéria orgânica do solo. Segundo Chander \& Joergensen (2001) a biomassa microbiana de solos poluídos com MP é menos eficiente na utilização de substratos para a própria síntese de constituintes celulares assim como necessita de mais energia para sua própria manutenção.

A determinação da atividade de várias enzimas no solo é uma maneira de se medir a atividade microbiana, indicando mudanças ocorridas na microbiota do solo, sem entretanto, relacioná-las a algum grupo específico de organismo. Kandeler et al. (1996) avaliaram, além da biomassa e respiração, a atividade de 13 enzimas envolvidas nos ciclos do $\mathrm{C}, \mathrm{N}, \mathrm{P}$ e $\mathrm{S}$ e constataram que nos solos contaminados com MP, houve significativa redução na biomassa microbiana e nas atividades enzimáticas envolvidas na ciclagem de N, P e S. Em contraste, a respiração e a atividade das enzimas relacionadas ao ciclo do $\mathrm{C}$ não foram muito afetadas, o que se relacionou com uma mudança na comunidade microbiana do solo, favorecendo as populações fúngicas sobre as bacterianas.

Além da associação planta hospedeira-fungo, a simbiose micorrízica é reconhecida também pela sua influência nas características físicas (Miller \& Jastrow, 1992) e na microbiota do solo (Nogueira \& Cardoso, 2002). Como os exsudatos radiculares contribuem para o crescimento bacteriano (Bowen \& Rovira, 1991) e como a colonização da raiz por fungos micorrízicos arbusculares (FMA) modifica a exsudação radicular, pode-se concluir que os FMA interagem diretamente com a microbiota do solo. A micorriza, portanto, pode alterar a quantidade e a composição das populações bacterianas da rizosfera e hifosfera (Lindermann, 1988) e, conseqüentemente, as atividades metabólicas da microbiota do solo.

O objetivo deste trabalho foi avaliar o efeito da adição de $\mathrm{Pb}$ ao solo na biomassa e atividade microbianas do solo sob influência da rizosfera de soja micorrizada.

\section{Material e Métodos}

$\mathrm{O}$ experimento foi realizado em casa de vegetação, seguindo esquema fatorial, $4 \times 2 \times 2$, com delineamento inteiramente casualizado e quatro repetições. Os tratamentos constituíram-se da combinação entre doses de $\mathrm{Pb}\left(0,150,300\right.$ e $\left.600 \mathrm{mg} \mathrm{dm}^{-3}\right)$, com a inoculação ou não de Glomus macrocarpum e dois estádios fenológicos da planta: florescimento e maturação do grão. As amostras de solo $(0-20 \mathrm{~cm})$ foram coletadas de um Latossolo Vermelho-Amarelo do Centro Experimental Central do Instituto Agronômico (IAC), Campinas, SP, cuja análise química apresentou os seguintes resultados: $\mathrm{pH}\left(\mathrm{CaCl}_{2}\right), 4,0$, matéria orgânica, $14 \mathrm{mg} \mathrm{dm}^{-3}$ e 2, 10,10 e $30 \mathrm{mg} \mathrm{dm}^{-3}$ de P, K, Mg e Ca, respectivamente. $\mathrm{O} \mathrm{pH}$ do solo foi corrigido com uma mistura de $\mathrm{Ca}(\mathrm{OH})_{2}$ e $\mathrm{Mg}\left(\mathrm{CO}_{3}\right)_{2}$ para elevar a $\mathrm{V} \%$ a 70\%. Após 15 dias de incubação, aplicaram-se K, S, B, $\mathrm{Cu}, \mathrm{Mn}$ e $\mathrm{Zn}$ nas quantidades de $100,41,0,4,1,8$ e $3 \mathrm{mg} \mathrm{dm}^{-3}$, respectivamente. Após 20 dias, o solo foi desinfestado com brometo de metila $\left(100 \mathrm{~mL} \mathrm{~m}^{-3}\right)$ e acondicionado em vasos de $2 \mathrm{~L}$, aos quais foram adicionados $25 \mathrm{mg} \mathrm{dm}^{-3}$ de P (superfosfato simples), e uma solução aquosa de $\mathrm{Pb}\left(\mathrm{NO}_{3}\right)_{2}$, cuja concentração variou de acordo com o tratamento. As amostras de solo permaneceram incubadas por 10 dias. Após esse período retirou-se uma amostra para análise química (Tabela 1).

As sementes de soja, Glycine $\max$ (L.) Merrill, variedade IAC-14, previamente desinfestadas com hipoclorito de sódio $25 \%$, foram imersas por 10 minutos em meio de cultura (manitol - extrato de levedura) com Bradyrhizobium japonicum, SEMIA 5079 e 5080, antes da semeadura. Foram semeadas seis sementes por vaso e, após o desbaste, restaram duas plantas. Nos tratamentos nos quais houve inoculação do FMA, foram adicionados $20 \mathrm{~mL}$ por vaso de inóculo, o qual constou de substrato (areia:solo, 9:1) com esporos, pedaços de raiz colonizada de Brachiaria brizantha e micélio de G. macrocarpum, fornecendo ao redor de 115 esporos $\mathrm{cm}^{-3}$ de solo-inóculo. Com o objetivo de restabelecer a comunidade microbiana no solo dos tra- 
tamentos sem inoculação do FMA, foram adicionados $20 \mathrm{~mL}$ do filtrado proveniente do substrato de multiplicação do FMA utilizado, no qual não havia propágulos de fungos micorrízicos.

Durante o ensaio, a umidade do solo foi mantida em torno de $60 \%$ da capacidade de retenção de água do solo. $\mathrm{O} \mathrm{N}$ foi aplicado de forma parcelada, com três aplicações de 25,50 e $50 \mathrm{mg}$ de $\mathrm{N}$ por vaso, no desbaste e após 15 e 30 dias, respectivamente, usando como fonte $\mathrm{Ca}\left(\mathrm{NO}_{3}\right)_{2}$. A quantidade de $\mathrm{N}$ aplicada em todos os tratamentos foi equiparada com a quantidade de $\mathrm{N}$ adicionada na forma de nitrato de chumbo. Após 60 dias do plantio, no florescimento, coletou-se metade das plantas e na maturidade da soja, após 100 dias, a outra metade. Para a posterior análise da biomassa, respiração, atividades enzimáticas, colonização micorrízica e contagem dos esporos do FMA, $250 \mathrm{~g}$ de solo foram acondicionados em sacos de plástico mantidos a $4^{\circ} \mathrm{C}$.

O número de esporos de FMA no solo produzidos no final do ciclo da planta foi determinado por contagem após o peneiramento úmido de $50 \mathrm{~mL}$ de amostras de solo (Gerdemann \& Nicolson, 1963), e centrifugação em solução de sacarose a $70 \%$. A colonização micorrízica da raiz foi determinada pelo método da placa quadriculada (Giovannetti \& Mosse, 1980), após despigmentação e coloração das raízes com azul de tripano (Phillips \& Hayman, 1970).

O C da biomassa microbiana foi determinado pelo método da fumigação-extração (Vance et al., 1987). As amostras de solo fumigadas foram incubadas por cinco dias a uma temperatura de $28 \pm 2^{\circ} \mathrm{C}$. Após extração do C orgânico, este foi quantificado pela oxidação ácida com dicromato de potássio (Joergensen, 1995). $\mathrm{O}$ fator de correção utilizado foi de 0,38 e o resultado expresso em $\mathrm{mg} \mathrm{C} \mathrm{g}^{-1}$ de solo seco. $\mathrm{O} \mathrm{CO}_{2}$ liberado foi determinado por titulação, conforme Alef (1995) e expresso em mg CO $\mathrm{gg}^{-1}$ de solo dia ${ }^{-1}$. O quociente metabólico, q- $\mathrm{CO}_{2}$, foi calculado segundo Anderson (1994), baseado na relação $\mu \mathrm{g} \mathrm{h}^{-1}$ de $\mathrm{C}-\mathrm{CO}^{2} / \mu \mathrm{g} \mathrm{g}{ }^{-1}$ de $\mathrm{C}$ da biomassa no solo seco.
A atividade da desidrogenase no solo foi determinada segundo Casida et al. (1964), com algumas modificações. Foram adicionados $5 \mathrm{~mL}$ de solução com $20 \mathrm{~g} \mathrm{~L}^{-1}$ de cloreto de 2,3,5-trifeniltetrazólio (TTC) a 5 g de solo, peneirado em malha de $2 \mathrm{~mm}$. A mistura foi homogenizada e incubada em banho-maria a $37^{\circ} \mathrm{C}$ no escuro, por um período de 24 horas. $\mathrm{O}$ trifenil formazan (TTF) formado pela redução do TTC foi extraído com $20 \mathrm{~mL}$ de metanol. Após centrifugação, o sobrenadante foi transferido para uma cubeta e realizou-se a leitura em espectrofotômetro a $485 \mathrm{~nm}$. A análise foi realizada em duplicata e os resultados expressos em $\mu \mathrm{g} \mathrm{TTF} \mathrm{g}^{-1}$ de solo 24 horas $^{-1}$.

A determinação da atividade da arilssulfatase foi realizada conforme Tabatabai \& Bremner (1970) e os resultados foram expressos em $\mu \mathrm{g}$ de p-nitrofenol $\mathrm{g}^{-1} \mathrm{de}$ solo hora ${ }^{-1}$.

A atividade da fosfatase alcalina no solo foi determinada conforme Eivazi \& Tabatabai (1977). A formação de p-nitrofenol foi determinada por espectrofotometria na região do espectro de $410 \mathrm{~nm}$, sendo o resultado expresso em $\mu \mathrm{g}$ de $\mathrm{p}$-nitrofenol $\mathrm{g}^{-1}$ de solo hora ${ }^{-1}$.

Os dados foram submetidos à analise de variância, teste de Tukey a 5\% de probabilidade, análise da regressão e correlação, utilizando-se o programa estatístico SANEST (Zonta et al., 1984).

\section{Resultados e Discussão}

A medida do $\mathrm{C}$ da biomassa tem sido usada como indicador de mudanças na comunidade microbiana do solo sob estresse por excesso de MP. O Pb disponível no solo correlacionou-se negativamente com o $\mathrm{C}$ da biomassa (Figura 1). O C da biomassa microbiana do solo com propágulos de FMA, amostrado na época do florescimento da planta, diminuiu em $60 \%$, na maior dose de $\mathrm{Pb}$ adicionada, o que poderia ser devido, em parte, a uma redução na quantidade de micélio externo do FMA decorrente do excesso de $\mathrm{Pb}$ no solo (Figura 1).

Tabela 1. Características químicas do solo após a calagem, adubação e aplicação do $\mathrm{Pb}$ antes da semeadura da soja.

\begin{tabular}{|c|c|c|c|c|c|c|c|c|c|c|c|}
\hline \multirow{2}{*}{$\begin{array}{c}\mathrm{Pb} \\
\left(\mathrm{mg} \mathrm{dm}^{-3}\right)\end{array}$} & \multirow{2}{*}{$\begin{array}{c}\mathrm{pH} \\
\mathrm{CaCl}_{2}\end{array}$} & \multirow{2}{*}{$\begin{array}{l}\mathrm{V} \\
(\%)\end{array}$} & CTC & $\mathrm{K}$ & $\mathrm{Ca}$ & $\mathrm{Mg}$ & $\mathrm{P}$ & $\mathrm{Pb}$ & $\mathrm{Fe}$ & $\mathrm{Zn}$ & $\mathrm{Cu}$ \\
\hline & & & \multicolumn{4}{|c|}{-- $\left(\mathrm{mmol}_{\mathrm{c}} \mathrm{dm}^{-3}\right)$-- } & \multicolumn{5}{|c|}{ - $\left(\mathrm{mg} \mathrm{dm}^{-3}\right)$} \\
\hline 0 & 5,7 & 73 & 67,2 & 3,2 & 37 & 9 & 24 & 1 & 21 & 2,0 & 1,6 \\
\hline 150 & 5,5 & 68 & 63,1 & 3,1 & 32 & 8 & 14 & 102 & 24 & 1,7 & 1,7 \\
\hline 300 & 5,5 & 67 & 61,9 & 2,9 & 31 & 8 & 11 & 215 & 25 & 1,5 & 1,8 \\
\hline 600 & 5,3 & 67 & 62,3 & 3,3 & 31 & 8 & 17 & 495 & 26 & 1,5 & 1,7 \\
\hline
\end{tabular}




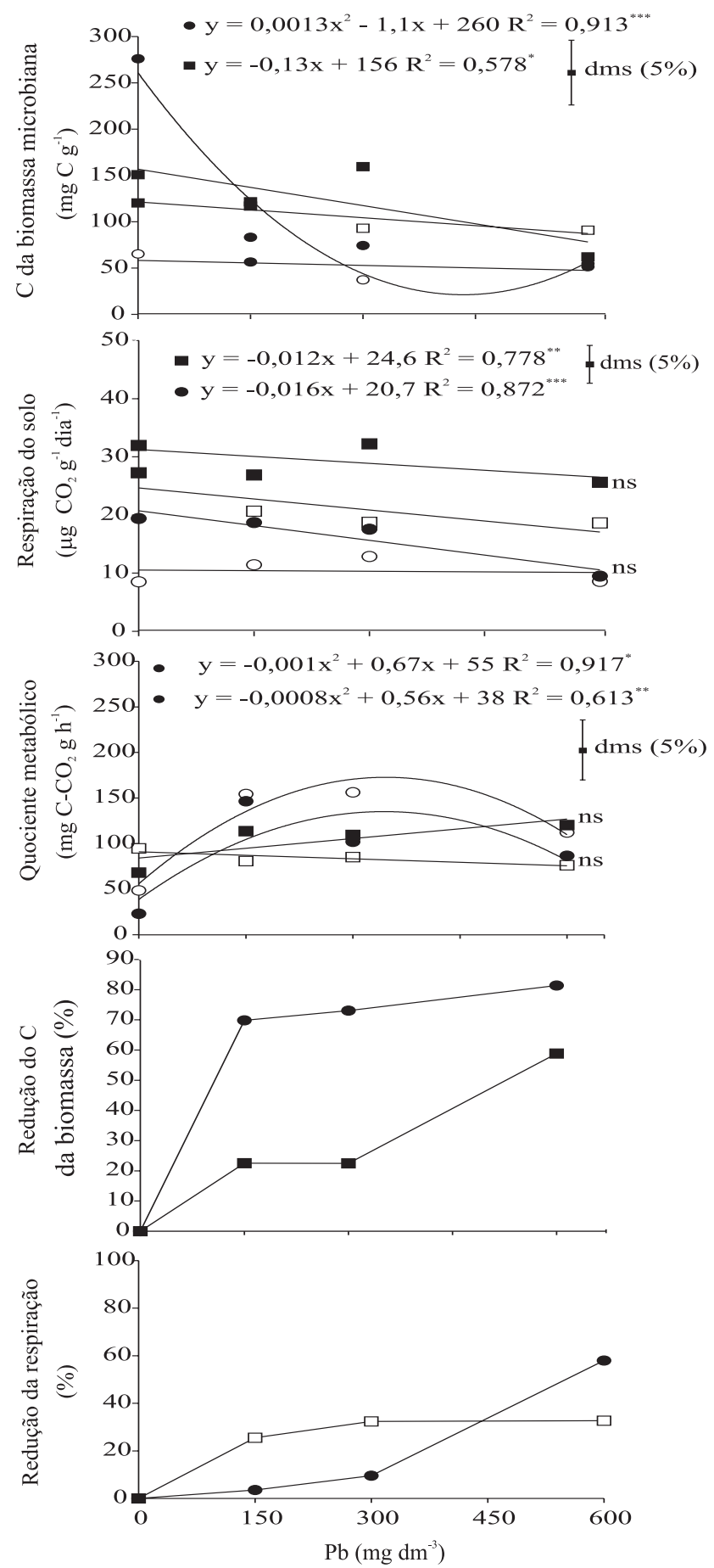

Figura 1. Carbono da biomassa microbiana, respiração do solo, quociente metabólico e redução da respiração e do C da biomassa microbiana em função das doses de $\mathrm{Pb}$ ( com FMA e $\square$ sem FMA, no florescimento da soja; • com FMA e O sem FMA, na maturação da soja). Valores de dms, comparando os fatores FMA e época dentro de cada dose de $\mathrm{Pb}$ pelo teste de

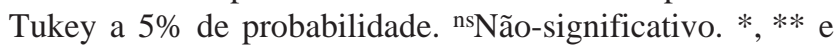
***Significativo a $5 \%, 1 \%$ e $0,1 \%$ de probabilidade, respectivamente.
No solo amostrado na maturação da planta, a diminuição foi ainda mais acentuada, cerca de $80 \%$, na menor dose de $\mathrm{Pb}$ adicionada. Como houve correlação significativa e positiva do $\mathrm{C}$ da biomassa com o número de esporos $\left(R^{2}=0,699, p<0,01\right)$ e com a colonização da raiz pelo FMA $\left(R^{2}=0,631, p<0,01\right)$, infere-se que o grande número de esporos produzidos pelo FMA (Andrade et al., 2004), contribuiu para o aumento da biomassa microbiana do solo na fase de maturação da planta, além da presença de micélio extra-radicular.

O C da microbiano do solo, com propágulos de FMA, foi maior apenas na época da maturação da planta (Figura 1). Esperava-se, entretanto, que as estruturas externas do FMA contribuíssem de forma significativa para o $\mathrm{C}$ da biomassa também na fase do florescimento. Pode ter ocorrido uma mudança no padrão de exsudação das raízes após a colonização, o que teria levado a uma menor exsudação e, conseqüentemente, ao menor crescimento da biomassa microbiana do solo, já que a exsudação radicular decresce após o estabelecimento do FMA na raiz (Graham et al., 1981). Desse modo, pode-se esperar efeito seletivo sobre os microrganismos, de forma que no solo, ao redor das raízes não colonizadas, haveria maior quantidade de exsudatos, o que favoreceria a microbiota da rizosfera, refletindo em maior biomassa.

Como a respiração do solo sem inoculação do FMA, no florescimento da soja, diminuiu com o aumento da concentração de $\mathrm{Pb}$ no solo e não foi observada diminuição na biomassa (Figura 1), infere-se que a comunidade microbiana estaria em estado de dormência ou com atividade metabólica reduzida por causa do $\mathrm{Pb}$ disponível. A passagem de um estado metabolicamente ativo a um estado de dormência pode ter um significado de sobrevivência, já que ajudaria o microrganismo a evitar a toxicidade por MP (Ohya et al., 1988; Chew et al., 2001). No entanto, no solo com propágulos de FMA amostrado no florescimento, a respiração basal manteve-se constante e a biomassa microbiana reduziu, o que poderia indicar uma menor eficiência de utilização do C pelas populações microbianas. Solos poluídos por MP estariam sob estresse, havendo menor eficiência de utilização do $\mathrm{C}$, o que resulta em maior liberação de $\mathrm{CO}_{2}$ por unidade de substrato (Insam et al., 1996).

Os solos com propágulos de FMA apresentaram maior atividade respiratória do que solos sem propágulos de FMA, possivelmente por causa da contribuição da atividade metabólica das estruturas externas do FMA e do 
possível estímulo do FMA à comunidade heterotrófica da hifosfera (Figura 1). Entretanto, no solo com FMA amostrado na maturação da planta, tanto a respiração como a biomassa microbiana diminuíram com o aumento do $\mathrm{Pb}$ no solo (Figura 1), o que pode estar relacionado, em parte, à diminuição do número de esporos de FMA (Andrade et al., 2004) (Tabela 2).

Ohya et al. (1988) observaram que, em solos poluídos com MP, a respiração do solo correlacionou-se negativamente com a concentração de metais e que esse efeito inibitório depende da concentração de matéria orgânica do solo. Sugeriram que a respiração basal está muitas vezes relacionada com o $\mathrm{C}$ da biomassa e com a comunidade metabolicamente inativa ou em estado de dormência. A adição de matéria orgânica aumenta a liberação de $\mathrm{CO}_{2}$ atribuída, principalmente, às populações metabolicamente ativas que são as mais afetadas pelo excesso de metais no solo (Insam et al., 1996). Assim, como o solo utilizado possuía uma baixa concentração de $\mathrm{C}$ orgânico, provavelmente havia pequena comunidade microbiana e baixa atividade respiratória, sugerindo que a microbiota estaria metabolicamente pouco ativa e que não seria afetada pela adição de chumbo. Já o fungo micorrízico, por depender dos carboidratos fornecidos pela planta, encontrar-se-ia metabolicamente mais ativo do que o resto da microbiota do solo, estando vulnerável ao efeito do $\mathrm{Pb}$, como foi observado.

$\mathrm{O} \mathrm{qCO}_{2}$ revelou que a comunidade microbiana do solo sofreu um estresse na dose de $300 \mathrm{mg} \mathrm{dm}^{-3} \mathrm{de} \mathrm{Pb}$, aumentando em três vezes em relação ao controle (Figura 1). Isso pode ser um indicador do desbalanço energético que sofre a comunidade microbiana por causa dos distúrbios ambientais (Anderson \& Domsch, 1993; Chander \& Joergensen, 2001). Devido à grande variabilidade entre os microssítios do solo, que proporcionam diversos microhabitats com diferentes tipos e intensidade de atividades metabólicas, a biomassa e a respiração do solo nem sempre se mostraram bons indicadores do

Tabela 2. Esporulação do FMA e colonização micorrízica da raiz de soja em solo com adição de chumbo.

\begin{tabular}{ccc}
\hline $\mathrm{Pb}\left(\mathrm{mg} \mathrm{dm}^{-3}\right)$ & $\begin{array}{c}\text { № de esporos/50 } \mathrm{mL} \\
\text { de solo }\end{array}$ & $\begin{array}{c}\text { Colonização } \\
\text { micorrízica }(\%)\end{array}$ \\
\hline 0 & 1055 & 36,1 \\
150 & 747 & 23,1 \\
300 & 682 & 26,4 \\
600 & 339 & 21,6 \\
\hline Equação de regressão & $\mathrm{y}=-1,12 \mathrm{x}-1000$ & $\mathrm{y}=-0,019 \mathrm{x}-35,5$ \\
$\mathrm{R}^{2}$ & 0,970 & 0,812 \\
\hline
\end{tabular}

efeito do Pb no solo (Dias-Júnior et al., 1998). As poucas correlações significativas entre as características biológicas e as doses de $\mathrm{Pb}$ adicionadas ao solo evidenciam a complexidade do sistema solo-planta-metal, o que já foi verificado por Insam et al. (1996) e Dias-Júnior et al. (1998).

A atividade da desidrogenase no solo reflete a atividade oxidativa total da microbiota, e como é intracelular de baixa atividade quando em estado livre no solo, pode atuar como um bom indicador da atividade microbiana presente no solo (Garcia et al., 1997). No entanto, outros autores não consideraram a atividade desta enzima um bom indicador da atividade total da microbiota do solo (Beyer et al., 1992). No presente trabalho, o solo com propágulos de FMA, na fase de florescimento, apresentou atividade da desidrogenase afetada pela adição de Pb (Figura 2). Doelman \& Haanstra (1979) observaram redução na atividade desta enzima com aumento do $\mathrm{Pb}$ no solo, mas constataram que a respiração foi mais sensível para a caracterização do efeito inibitório do $\mathrm{Pb}$ sobre a microbiota do solo. Neste trabalho, apesar da correlação significativa entre respiração e atividade da desidrogenase, a atividade da enzima não se correlacionou com a concentração de $\mathrm{Pb}$ no solo, revelando que a atividade da desidrogenase não foi um bom indicador do efeito do chumbo. Apesar de a atividade da desidrogenase não refletir satisfatoriamente o efeito de altas concentrações de $\mathrm{Pb}$ no solo, a correlação com a respiração basal foi positiva e, portanto, indicadora da atividade metabólica do solo.

A fosfatase alcalina é uma fosfomonoesterase de importância na mineralização do $\mathrm{P}$ orgânico do solo e os microrganismos são totalmente responsáveis por essa atividade, já que a enzima não é sintetizada pelas plantas (Tyler, 1974). O Pb causou efeito inibitório da atividade da fosfatase alcalina em todos os tratamentos exceto no solo com propágulos de FMA amostrado no florescimento (Figura 2). Houve $60 \%$ de inibição da enzima por causa do aumento da dose de $\mathrm{Pb}$, sugerindo que a enzima foi sensível às concentrações de $\mathrm{Pb}$ adicionadas, corroborando os resultados de Kandeler et al. (1996). A atividade da fosfatase alcalina do solo amostrado no florescimento também foi maior em relação ao amostrado na maturação da planta, confirmando a importância do metabolismo da raiz e do efeito rizosférico no solo circundante, que influenciam diretamente a atividade microbiana. A atividade da enzima também foi estimulada pela presença de propágulos do FMA no florescimento.

No solo, a enzima arilssulfatase participa da mineralização do S orgânico e já foi observada diminui- 


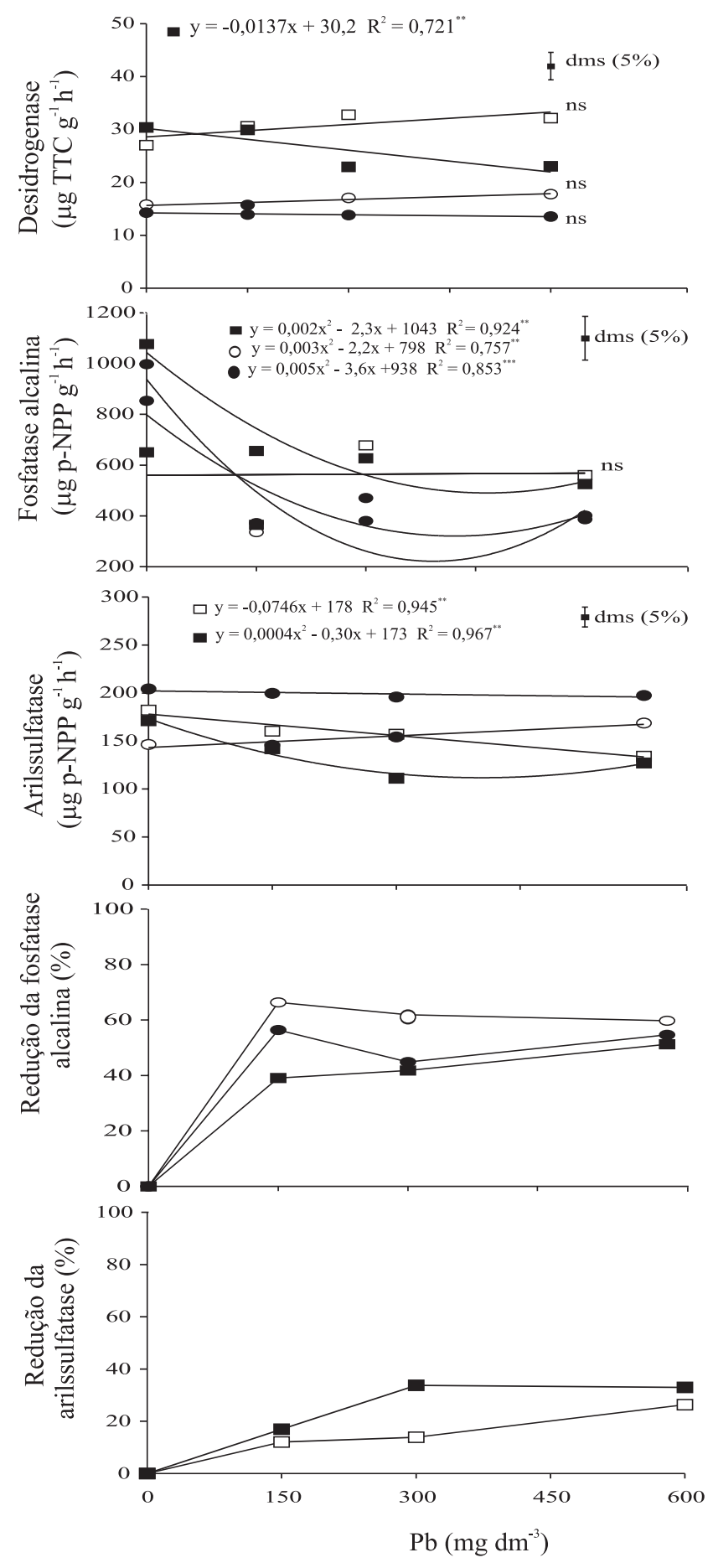

Figura 2. Atividade de desidrogenase, fosfatase alcalina e arilssulfatase e redução das atividades de fosfatase alcalina e arilssulfatase no solo ( $\square$ com FMA e $\square$ sem FMA, no florescimento da soja; com FMA e $\bigcirc$ sem FMA, na maturação da soja). Valores de dms comparando os fatores FMA e época dentro de cada dose de $\mathrm{Pb}$ pelo teste de Tukey a $5 \%$ de probabilidade. ${ }^{\text {ns Não-significativo. } * * \text { e } * * * \text { Signifi- }}$ cativo a $1 \%$ e $0,1 \%$ de probabilidade, respectivamente. ção na sua atividade em solos contaminados com metais (Kandeler et al., 1996). Neste trabalho, a atividade da arilssulfatase no solo com propágulos de FMA foi mais influenciada pelo excesso de $\mathrm{Pb}$ do que no solo sem FMA, e na maturação da planta a presença de FMA estimulou em $30 \%$ a atividade da enzima (Figura 2).

A microbiota do solo foi influenciada negativamente pela adição de $\mathrm{Pb}$ ao solo. Atividades relacionadas com a ciclagem de nutrientes poderiam ser prejudicadas pela contaminação por MP, os quais têm alta permanência no solo, sendo de difícil remoção, o que pode acarretar diminuição na mineralização da matéria orgânica. A maior atividade enzimática observada no solo com propágulos de FMA reflete a importância do efeito da micorrizosfera na atividade da comunidade microbiana (Vázquez et al., 2000). Portanto, a micorrização da soja causou mudanças diretas no fornecimento de compostos orgânicos ao solo e, de forma quantitativa, na microbiota rizosférica, resultando em maior atividade da microbiota do solo.

\section{Conclusões}

1. $\mathrm{O} \mathrm{Pb}$ altera negativamente o $\mathrm{C}$ da biomassa e a atividade da microbiota rizosférica, ocorrendo interação entre a presença de propágulos de FMA e o estádio de desenvolvimento da planta.

2. $\mathrm{O} \mathrm{Pb}$ tem efeito negativo sobre o $\mathrm{C}$ da biomassa microbiana do solo com propágulos de FMA.

3. A atividade da fosfatase alcalina é um indicador adequado na avaliação do estresse causado pelo $\mathrm{Pb}$ no solo.

4. A micorrização da soja influencia de forma direta a microbiota rizosférica, resultando em maior atividade e biomassa.

\section{Agradecimentos}

À Capes, pela bolsa de mestrado outorgada à primeira autora; às técnicas de laboratório Rosana Gierts Gonçalves e Tereza Bueno Mangussi, pelo auxílio nas análises microbiológicas.

\section{Referências}

ALEF, K. Soil respiration. In: ALEF, K.; NANNIPIERI, P. (Ed.). Methods in applied soil microbiology and biochemistry. London: Academic Press, 1995. p.214-219. 
ANDERSON, T.H. Physilogical analysis of microbial communities in soil: applications and limitations. In: RITZ, K.; DIGHTON, J.; GILLER, K.E. (Ed.). Beyond the biomass. London: British Society of Soil Science, 1994. p.67-76.

ANDERSON, T.H.; DOMSCH, K.H. The metabolic quotient for $\mathrm{CO}_{2}\left(\mathrm{qCO}_{2}\right)$ as a especific activity parameter to assess the effects of environmetal conditions, such as $\mathrm{pH}$, on the microbial biomass of forest soils. Soil Biology and Biochemistry, v.25, p.393-395, 1993.

ANDRADE, S.A.L.; ABREU, C.A.; ABREU, M.F.; SILVEIRA, A.P.D. Influence of lead additions on arbuscular mycorrhiza and Rhizobium symbioses under soybean plants. Applied Soil Ecology, v.26, p.123-131, 2004.

BÄÄTH, E.; FROSTERGÄRD, A.; DIAZ-RAVIÑA, M.; TUNLID, A. Microbial community-based measurements to estimate heavy metal effects in soil: the use of phospholipid fatty acid patterns and bacterial comunity tolerance. Ambio, v.27, p.58-61, 1998.

BARAJAS ACEVES, M.; GRACE, C.; ANSORENA, J.; DENDOOVEN, L.; BROOKES, P.C. Soil microbial biomass and organic $\mathrm{C}$ in a gradient of zinc concentrations in soils around a mine spoil tip. Soil Biology and Biochemestry, v.31, p.867-876, 1999.

BEYER, L.; WACHENDORF, C.; BALZER, F.M.; BALZERGRAF, U.R. The effect of soil texture and soil management on microbial biomass and soil enzyme activities in arable soils of Northwest Germany. Agrobiological Research, v.45, p.276-283, 1992.

BOWEN, G.D.; ROVIRA, A.D. The rhizosphere, the hidden half of the hidden half. In: WAISEL, Y.; ESHEL, A.; KAFKAFI, U. (Ed.). Plant roots: the hidden half. New York: Marcel Dekker, 1991. p.641649.

BROOKES, P.C.; MACGRATH, S.P. Effects of metal toxicity on the size of the soil microbial biomass. Journal of Soil Science, v.35, p.341-346, 1984.

CASIDA, L.E.; KLEIN, D.A.; SANTORO, T. Soil dehydrogenase activity. Soil Science, v.98, p.371-376, 1964.

CHANDER, K.; JOERGENSEN, R.G. Decomposition of ${ }^{14} \mathrm{C}$ glucose in two soils with different amounts of heavy metal contamination. Soil Biology and Biochemistry, v.33, p.1811-1816, 2001.

CHEW, I.; OBBARD, J.P.; STANFORTH, R.R. Microbial cellulose decomposition in soils from a rifle range contaminated with heavy metals. Environmental Pollution, v.111, p.367-375, 2001.

COSTANZA, R.; D‘ARGE, R.; DE GROOT, R.; FABER, S.; GRASSO, M.; HANNON, B.; LIMBURG, K.; NAEEM, S.; O`NEILL, R.V.; PARUELO, J.; RASKIN, R.G.; SUTTON, P.; BELT, $M$. van den. The value of the world's ecosystem services and natural capital. Nature, v.387, p.253-260, 1997.

DIAS-JÚNIOR, H.E.; MOREIRA, F.M.S.; SIQUEIRA, J.O.; SILVA, R. Metais pesados, densidade e atividade microbiana em solo contaminado por rejeitos de indústria de zinco. Revista Brasileira de Ciência do Solo, v.22, p.631-640, 1998.

DOELMAN, P.; HAANSTRA, L. Effect of lead on soil respiration and dehydrogenase activity. Soil Biology and Biochemistry, v.11, p.475-479, 1979.

DORAN, J.W.; ZEISS, M.R. Soil health and sustainability: managing the biotic component of soil quality. Applied Soil Ecology, v.15, p.3-11, 2000.
EIVAZI, F.; TABATABAI, M.A. Phosphatases in soils. Soil Biology and Biochemistry, v.9, p.167-172, 1977.

FLIEBBACH, A.; MARTENS, A.; REBER, H.H. Soil microbial biomass and microbial activity in soils treated with heavy metal contaminated sewage-sludge. Soil Biology and Biochemistry, v.26, p.1201-1205, 1994.

GARCIA, T.C; HERNANDEZ, T.; COSTA, F. Potential use of dehydrogenase activity as index of microbial activity in degraded soils. Communications in Soil Science and Plant Analysis, v.28, p.123-134, 1997.

GERDEMANN, J.W.; NICOLSON, T.H. Spores of mycorrhizal Endogone species extracted from soil by wet-sieving and decanting. Transactions of the British Mycological Society, v.46, p.235244, 1963.

GIOVANNETTI, M.E.; MOSSE, B. An evaluation of techniques for measuring vesicular-arbuscular mycorrrhizal infection in roots. New Phytologist, v.84, p.489-500, 1980.

GRAHAM, J.H.; LEONARD, R.T.; MENGE, J.A. Membranemediated decrease in root exudation responsible for phosphorus inhibition of vesicular-arbuscular mycorrhiza formation. Plant Physiology, v.68, p.548-552, 1981.

INSAM, H.; HUTCHINSON, T.C.; REBER, H.H. Effects of heavy metal stress on the metabolic quotient of the soil microflora. Soil Biology and Biochemistry, v.28, p.691-694, 1996.

JOERGENSEN, R. The fumigation extraction method. In: ALEF, K.; NANNIPIERI, P. (Ed.). Methods in applied soil microbiology and biochemistry. London: Academic Press, 1995. p.382-387.

KANDELER, E.; KAMPICHLER, C.; HORAK, O. Influence of heavy metals on the functional diversity of soil microbial communities. Biology and Fertility of Soils, v.23, p.299-306, 1996.

LINDERMAN, R.G. Mycorrhizal interactions with the rizosphere microflora: the mycorrhizosphere effect. Phytopathologist, v.78, p.366-371, 1988.

MILLER, R.M.; JASTROW, J.D. The role of mycorrhizal fungi in soil conservation. In: BETHLENFALVAY, G.J.; LINDERMAN, R.G. (Ed.). Mycorrhizae in sustainable agriculture. Madison: Agronomy Society of America, 1992. p.29-44. (Special Publication, 54).

NOGUEIRA, M.A.; CARDOSO, E.J.B.N. Interações microbianas na disponibilidade e absorção de manganês por soja. Pesquisa Agropecuária Brasileira, v.37, p.1605-1612, 2002.

OHYA, H.; FUJIWARA, S.; KOMAI, Y.; YAMAGUCHI, M. Microbial biomass and activity in urban soils contaminated with $\mathrm{Zn}$ and Pb. Biology and Fertility of Soils, v.6, p.9-13, 1988.

PHILLIPS, J.M.; HAYMAN, D.S. Improved procedures for clearing roots and staining parasitic and vesicular arbuscular mycorrhizal fungi for rapid assessment of infection. Transactions of the British Mycological Society, v.55, p.158-161, 1970.

REBER, H.H. Simultaneous estimates of the diversity and the degradative capability of heavy-metal-affected soil bacterial communities. Biology and Fertility of Soils, v.13, p.181-186, 1992. 
REDDY, G.N.; PRASAD, M.N.V. Heavy metal binding proteins/ peptides: Ocurrence, structure, synthesis and functions. A review. Environmental and Experimental Botany, v.30, p.251-264, 1990.

TABATABAI, M.A.; BREMNER, J.M. Arylsulphatase activity in soils. Soil Science Society of America Proceedings, v.34, p.225229, 1970.

TYLER, G. Heavy metal pollution and soil enzyme activity. Plant and Soil, v.41, p.303-311, 1974.

VALSECCHI, G.; GIGLIOTTI, C.; FARINI, A. Microbial biomass, activity and organic matter accumulation in soils contaminated with heavy metals. Biology and Fertility of Soils, v.20, p.253-259, 1995.
VANCE, E.D.; BROOKES, P.C.; JENKINSON, D.S. An extraction method for measuring soil microbial biomass carbon. Soil Biology and Biochemistry, v.19, p.703-707, 1987.

VÁZQUEZ, M.M.; CÉSAR, S.; AZCÓN R.; BAREA, J.M. Interactions between arbuscular mycorrhizal fungi and other microbial inoculants (Azospirillum, Pseudomonas, Trichoderma) and their effects on microbial population and enzyme activities in the rhizosphere of maize plants. Applied Soil Ecology, v.15, p.261$272,2000$.

ZONTA, E.P.; MACHADO, A.A.; SILVEIRA JÚNIOR, P. Sistemas de análise estatística para microcomputadores (SANEST). Pelotas: Universidade Federal de Pelotas, 1984. 151p.

Recebido em 25 de junho de 2004 e aprovado em 23 de agosto de 2004 